\title{
DIREITOS DO CIDADÃO HOSPITALIZADO: CONHECIMENTO E PRÁTICA DOS ENFERMEIROS
}

\author{
THE RIGHTS OF HOSPITALIZED CITIZENS \\ DERECHOS DEL CIUDADANO HOSPITALIZADO: CONOCIMIENTO Y PRÁCTICA DE LOS \\ ENFERMEROS
}

Autora: Ilvana Lima Verde Gomes Orientadora: Maria de Nazaré de Oliveira Fraga

\begin{abstract}
O exercício de cidadania é um direito assegurado em vários documentos. É para ser exercido em todo o território nacional, independente de cor, raça, credo, sexo ou condição social. Isto implica que dentro do hospital o indivíduo deve participar ativamente do seu tratamento, coadunando com o profissional de saúde para uma tomada de decisão sobre sua saúde. Este estudo é de natureza qualitativa e teve como objetivos: identificar o conhecimento que os enfermeiros têm sobre os direitos do cidadão segundo o Código de Ética dos Profissionais de Enfermagem (C.E.P.E.), levantar o modo como os enfermeiros avaliam o conteúdo sobre os direitos do cidadão hospitalizado, abordado durante o ensino de graduação em enfermagem, levantar a maneira como os enfermeiros apreciam as condições existentes na Instituição e sua adequação ao respeito aos direitos do cidadão hospitalizado e verificar se os enfermeiros transpõem para a prática o conhecimento sobre os direitos do cidadão hospitalizado. O estudo foi realizado em um hospital geral de Fortaleza, de natureza pública. Os sujeitos da pesquisa foram oito enfermeiros, de dois setores, que aceitaram responder a entrevista, após o que realizamos observações das práticas dos sujeitos, que resultaram em 37 situações. A pesquisa foi fundamentada na abordagem histórico-estrutural. Como resultados observamos que os enfermeiros possuem algum conhecimento sobre os direitos dos clientes, porém poucos direitos citados constavam no C.E.P.E.; apenas dois enfermeiros citaram documentos referentes aos direitos do cidadão; informaram que a instituição oferecia condições para que o direito do cliente fosse respeitado, mas houve contradição quando afirmaram que existia falta de material e que dependia do profissional oferecer essas condições. Quando realizamos as observações, notamos incoerência entre o discurso e a práxis de alguns sujeitos, pois cercearam os direitos dos clientes, deixando de prestar-Ihes informações, de atender suas queixas, orientá-los sobre os procedimentos, negligenciando os cuidados aos delegá-los a outros que, segundo a Lei do Exercício Profissional, não tinham competência para fazê-los, ou não registrando os procedimentos, nem priorizando os cuidados. Por outro lado, encontramos enfermeiros criteriosos, que procuraram tratar os clientes como cidadãos. Concluimos que há muito ainda a ser explorado, discutido e realizado para que o exercício de cidadania do cliente hospitalizado e o respeito aos seus direitos possam ser apreendidos e incorporados à vida cotidiana dos profissionais de saúde e dos próprios clientes. No sentido de contribuir efetivamente para a resolução de problema tão evidente, pretendemos repassar, formalmente, à Instituição que serviu como campo para coleta de dados, os resultados obtidos na pesquisa e, ainda, nos colocar à disposição dos enfermeiros e de outros profissionais de saúde, até de modo informal, para a divulgação deste trabalho para o aprofundamento da discussão sobre esta temática e para a definição de estratégias a fim de encontrar soluções.
\end{abstract}

\section{AUTONOMIA DO PACIENTE: O VIVENCIAL DO ALUNO DE GRADUAÇÃO EM ENFERMAGEM}

\author{
THE PATIENT'S AUTONOMY: THE EXPERIENCE OF UNDERGRADUATE NURSING \\ STUDENTS
}

\footnotetext{
${ }^{1}$ Cópia das teses/dissertações solicitar informações pelo e-mail cepen@abennacional.org.br.
} 


\title{
AUTONOMÍA DEL PACIENTE: LO VIVENCIAL DEL ALUMNO DEL CURSO DE ENFERMERÍA
}

Autora: Cristina de Araújo Lasevicius

Orientadora: Maria C. Komatsu Braga Massarollo

RESUMO: Este estudo teve como objetivo desvelar a vivência dos alunos de graduação em enfermagem, em situações que envolvem a autonomia do paciente. Optou-se por realizar uma pesquisa qualitativa, na vertente fenomenológica, segundo a modalidade "estrutura do fenômeno situado". Foram entrevistados oito alunos do quarto ano de graduação, que responderam à seguinte questão norteadora: "Conte-me uma situação relacionada à autonomia do paciente, vivida por você, durante algum estágio curricular". Cada discurso foi analisado individualmente, sendo realizada a análise ideográfica, que gerou os seguintes temas: "Caracterizando a autonomia do paciente", "Convivendo com os sentimentos gerados em situações que envolvem a autonomia do paciente", "Buscando subsídios para nortear suas ações", "Intervindo e avaliando os resultados" e "Identificando o papel do profissional de saúde frente à autonomia do paciente". Pela análise nomotética, buscou-se as convergências e divergências das unidades de significado, em direção à estrutura geral do fenômeno. As proposições que emergiram, revelam que, para o aluno, o significado de autonomia apresenta ambigüidade, mas é fundamental identificar-se com o ser paciente, reconhecê-lo como um sujeito dotado de vontade própria - que deve tomar decisões de forma esclarecida, assumindo as responsabilidades decorrentes - compreendê-lo como um "fim" e não como um "meio" no processo de cuida/tratar e atuar como um agente de mudanças.

\section{FUNDAMENTOS DOS JUÍZOS MORAIS NA ENFERMAGEM}

\author{
THE PRINCIPLES OF MORAL JUDGEMENT IN NURSING
}

\begin{abstract}
FUNDAMENTOS DE LOS JUICIOS MORALES EN ENFERMERÍA
\end{abstract}
Autora: Leni Cristina Domingos Coelho Orientadora: Rosalina A. Partezani Rodrigues

RESUMO: A presente pesquisa tem por objetivo identificar e analisar as justificativas morais das enfermeiras a respeito de dois dilemas éticos. É uma pesquisa qualitativa tipo descritiva, onde foi utilizada a análise temática transversal intensiva. Utilizamos como referencial teórico a linha principialista pluralista; a linha utilitarista conseqüencialista e a ética do cuidado na área da enfermagem para que pudéssemos analisar as duas situações de conflito ético. A primeira diz respeito à informação e a segunda à iatrogenia cirúrgica. Foram realizadas vinte e oito entrevistas com enfermeiras. Os resultados apontam que a maioria das enfermeiras concentram-se nos hospitais e possuem idades e tempo de serviço consideradas necessárias para serem experts na assistência de enfermagem. $O$ estudo assegura que as enfermeiras adotam posições diferentes ao defenderem os direitos dos pacientes quanto à informação. No conjunto, as respondentes baseiam suas justificativas na ética normativa, deontológica, alternando em alguns momentos com a ética do cuidado e a conseqüencialista. As enfermeiras respeitam a forma contratual e a hierarquia para o encaminhamento dos problemas éticos. Elas são contrárias à condição feminina de submissão, e ás atitudes paternalistas da equipe, e ao mesmo tempo transcorrido para dar as informações. Evidenciamos conflitos de valores morais entre enfermeiros, médicos e pacientes quanto ao direito de acesso á informação. As respondentes ressaltam a franqueza, verdade, clareza e o diálogo como formas de manter o consentimento. Elas procuram garantir a autonomia dos pacientes, mas têm dificuldades para adotar atitudes diretas para defenderem as responsabilidades e os compromissos profissionais. As enfermeiras enfatizam que todos têm o dever de informar e que os processos iatrogênicos envolvem prioritariamente os aspectos morais e depois os legais. Para as respondentes as chefias de enfermagem devem discutir, reciclar, advertir e orientá-las aproveitando para promover mudança e crescimento nas tomadas de decisões. Concordam 